\title{
Sexual differentiation of the human brain in relation to gender identity and sexual orientation
}

\author{
Dick F. Swaab, MD, PhD \\ Alicia Garcia-Falgueras, PhD \\ The Netherlands ${ }^{1}$ \\ Corresponding author: Dick F. Swaab \\ Netherlands Institute for Neuroscience, \\ Meibergdreef 47, \\ 1105 BA Amsterdam ZO, The Netherlands \\ E-mail: d.f.swaab@nin.knaw.nl
}

The Netherlands Institute for Neuroscience, Amsterdam,

\section{Summary}

During the intrauterine period the fetal brain develops in the male direction through a direct action of testosterone on the developing nerve cells, or in the female direction through the absence of this hormone surge. In this way, our gender identity (the conviction of belonging to the male or female gender) and sexual orientation are programmed into our brain structures when we are still in the womb. However, since sexual differentiation of the genitals takes place in the first two months of pregnancy and sexual differentiation of the brain starts in the second half of pregnancy, these two processes can be influenced independently, which may result in transsexuality. This also means that in the event of ambiguous sex at birth, the degree of masculinization of the genitals may not reflect the degree of masculinization of the brain.

There is no proof that social environment after birth has an effect on gender identity or sexual orientation.

KEY WORDS: gender identity, homosexuality, human brain, sexual orientation, sexual differentiation, transsexuality.

Sexual organization and activation of the human brain

The process of sexual differentiation of the brain brings about permanent changes in brain structures and functions via interactions of the developing neurons with the environment, understood in its widest sense. The environment of a developing neuron is formed by the surrounding nerve cells and the child's circulating hormones, as well as the hormones, nutrients, medication and other chemical substances from the mother and the environment that enter the fetal circulation via the placenta. All these factors may have a lasting effect on the sexual differentiation of the brain.

The testicles and ovaries develop in the sixth week of pregnancy. This occurs under the influence of a cascade of genes, starting with the sex-determining gene on the $Y$ chromosome (SRY). The production of testosterone by a boy's testes is necessary for sexual differentiation of the sexual organs between weeks 6 and 12 of pregnancy. The peripheral conversion of testosterone into dihydrotestosterone is essential for the formation of a boy's penis, prostate and scrotum. Instead, the development of the female sexual organs in the womb is based primarily on the absence of androgens (1).

Once the differentiation of the sexual organs into male or female is settled, the next thing that is differentiated is the brain, under the influence, mainly, of sex hormones on the developing brain cells. The changes (permanent) brought about in this stage have organizing effects; later, during puberty, the brain circuits that developed in the womb are activated by sex hormones. This paradigm of sexual differentiation of the brain has been well established, ever since the first paper by Phoenix et al. (2). The fetal brain is protected against the effect of circulating estrogens from the mother by the protein $\alpha$-fetoprotein, which is produced by the fetus and binds strongly to estrogens but not to testosterone $(3,4)$. However, estrogens do not only reach the brain via circulation: the brain itself is also capable of producing estrogens. In human beings testosterone may thus not only have a direct effect on a masculine brain, but, once converted into estrogens by aromatase, may also act on developing neurons. In addition, there are sex differences in brain steroid receptor distribution not only in adulthood (5-8) but also during development (9). In rats, the formation of estradiol in the brain by aromatization of circulating testosterone is the most important mechanism for virilization of the brain (10), but, as seen below, it does not determine human gender identity or sexual orientation. There may also be direct genetic effects that affect the sexual differentiation of the brain without involving the sex hormone receptors. Some fetal rat brain cells undergo sexual differentiation, even in tissue culture, without the involvement of sex hormones $(11,12)$. The genes $S R Y$ and $Z R Y$ are candidates for this action since they are expressed until very advanced ages in the human brain, even though strictly speaking the role of these genes in sexual differentiation stops during development $(13,14)$. There are at present many additional candidate genes for a role in sexual differentiation of the brain without the involvement of hormones, since it has been found that fifty genes are expressed at different levels in the brains of male and female mouse fetuses, even before the hormones come into play (15). Also, genes that escape inactivation on the $X$ chromosome (such as $P C D H 11 X$ ) could show sexually dimorphic expression and thus contribute to sexually dimorphic functions (16). Thus, the sexual differentiation of the brain is

\footnotetext{
${ }^{1}$ The Netherlands Institute for Neuroscience is an institute of the Royal Netherlands Academy of Arts and Sciences.
} 
not caused by hormones alone, even though they are very important for gender identity and sexual orientation.

\section{Sex hormones and human brain development}

During fetal development, the brain is influenced by sex hormones such as testosterone, estrogens and progesterone (17). From the earliest stages of fetal brain development, many neurons throughout the entire nervous system already have receptors for these hormones (9). The early development of boys shows two periods during which testosterone levels are known to be high. The first surge occurs during mid-pregnancy: testosterone levels peak in the fetal serum between weeks 12 and 18 of pregnancy (18) and in weeks 34-41 of pregnancy the testosterone levels of boys are ten times higher than those of girls (19). The second surge takes place in the first three months after birth. At the end of pregnancy, when the $\alpha$-fetoprotein level declines, the fetus is more exposed to estrogens from the placenta, this exposure inhibiting the hypothalamus-hypophysial-gonadal axis of the developing child. Loss of this inhibition once the child is born causes a peak in testosterone in boys and a peak in estrogens in girls (20). The testosterone level in boys at this time is as high as it will be in adulthood, although a large part of the hormone circulates bound. During these two periods, therefore, girls do not show high levels of testosterone. These fetal and neonatal peaks of testosterone, together with the functional steroid receptor activity, are thought to fix the development of structures and circuits in the brain for the rest of a boy's life (producing "programming" or "organizing" effects). Later, the rising hormone levels that occur during puberty "activate" circuits and behavioral patterns that were built during development, in a masculinized and de-feminized direction for male brains or in a feminized and de-masculinized direction for female brains.

The brain structure differences that result from the interaction between hormones and developing brain cells are thought to be the basis of sex differences in a wide spectrum of behaviors, such as gender role (behaving as a man or a woman in society), gender identity (the conviction of belonging to the male or female gender), sexual orientation (heterosexuality, homosexuality or bisexuality), and sex differences regarding cognition, aggressive behavior and language organization. Factors that interfere with the interactions between hormones and the developing brain systems during development in the womb may permanently influence later behavior. As sexual differentiation of the genitals takes places much earlier in development (i.e. in the first two months of pregnancy) than sexual differentiation of the brain, which starts in the second half of pregnancy and becomes overt upon reaching adulthood, these two processes may be influenced independently of each other. In rare cases, this may result in transsexuality, i.e. people with male sexual organs who feel female or vice versa. It also means that in the event of an ambiguous sex at birth, the degree of masculinization of the genitals may not always reflect the degree of masculinization of the brain (21-24). In addition, gender identity may be determined by prenatal hormonal influences, even though the prenatal hormonal milieu might be inadequate for full genital differentiation (25).

\section{Programmed gender identity is irreversible}

The irreversibility of programmed gender identity is clearly illustrated by the sad story of the John-JoanJohn case (i.e. the case of David Reimer). In the 1960s and 1970s, in the context of the concept of behaviorism, it was postulated that a child is born as a tabula rasa and is subsequently forced in the male or female direction by society's conventions. Although it is true that, in humans, self-face recognition appears to emerge at around 18 months of age (26) and that by the age of 23 years children are able to correctly label themselves and others according to gender (27), there is no evidence that external or social events might modify these processes. However, J. Money argued that: "Gender identity is sufficiently incompletely differentiated at birth as to permit successful assignment of a genetic male as a girl. Gender identity then differentiates in keeping with the experiences of rearing" (28). This view had devastating results in the John-Joan-John case (29). Money maintained that gender imprinting does not start until the age of 1 year, and that its development is well advanced by the age of 3-4 years (30). This was, indeed, the basis for the decision to make a girl out of an 8-month-old boy who lost his penis due to a mistake during minor surgery (i.e. an operation to correct phimosis). The testicles of this child were removed before he reached the age of 17 months in order to facilitate feminization. The child was dressed in girls' clothes, received psychological counseling and was given estrogens in puberty. According to Money, this child developed as a normal female. However, Milton Diamond later made it clear that this had not been the case at all. In adulthood, this child changed back to male, married, and adopted several children (31). Unfortunately, he had a troubled life and committed suicide in May 2004. This story illustrates the enormous programming influence of the intrauterine period on gender. Other cases have been described in the literature (32), due to enzymatic disorders (33-35) or to cloacal exstrophy (36), that support the existence of early permanent programming of brain sex by biological factors and androgen exposure, rather than by social environment and learning $(17,37)$.

The mechanism of sexual differentiation of the brain: neurobiological factors

In male rats, testosterone is turned into estrogens by local aromatization in the brain, and these estrogens then masculinize certain brain areas. This finding agrees with the observation that in partially androgen insensitive (testosterone feminized - Tfm) male rats no reversion of the sex difference was present in the preoptic area (10) and the bed nucleus of the stria terminalis (38). These animals retained a male neuroanatomy. Other brain nuclei, such as the posteromedial amygdala, the ventromedial hypothalamus and the locus coeruleus were, however, feminized in Tfm male rats (38-40).

In humans, however, the main mechanism appears to involve a direct effect of testosterone on the developing brain. Complete androgen insensitivity syndrome is caused by mutations in the receptor gene for androgens. Despite their genetic (XY) masculinity, affected individuals develop as phenotypical women and experi- 
ence "heterosexual" sexual orientation, fantasies and experiences, without gender problems (41). On the other hand, when a boy fetus has a $5 \alpha$-reductase- 2 or 17ß-hydroxy-steroid dehydrogenase-3 deficiency preventing peripheral testosterone from being transformed into dihydrotestosterone, a "girl" with a large clitoris is born. These children are generally raised as girls. However, when testosterone production increases in these $\mathrm{XY}$ children during puberty, this "clitoris" grows to penis size, the testicles descend, and the child's build begins to masculinize and become muscular. Despite the fact that these children are initially raised as girls, the majority $(60 \%)$ change into heterosexual males $(24,34,35,42$, $43)$, apparently due to the organizing effect of testosterone on early brain development. Boys who are born with a cloacal exstrophy - i.e. with bladder exstrophy and a partly or wholly absent penis - are usually changed into girls immediately after birth. A survey showed that in adulthood only $65 \%$ of these children who were changed into girls continued to live as girls, and when individuals with gender dysphoria were excluded the figure dropped to $47 \%(44,45)$. From these examples it appears that the direct action of testosterone on the developing brain in boys and the lack of it in the developing brain in girls are crucial factors in the development of male and female gender identity and sexual orientation, although other sexually dimorphic functions still need to be investigated in these people. Conversely, studies on cloacal exstrophy suggest that the postnatal testosterone peak is not crucial for gender identity development, given that these children generally undergo operation shortly after birth.

\section{Sex differences in the human brain}

A sex difference in brain weight is already present in children from the age of 2 years (46) and sex differences can thus be expected throughout the brain from early in development. In the adult human brain structural sex differences can be found from the macroscopic level (47) down to the ultramicroscopic level (48). Functionally, too, a large number of sex differences in different brain regions have recently been described (49-53). Sexual differentiation of the human brain is also expressed in behavioral differences, including sexual orientation (homo-, bi- and heterosexuality) and gender identity (22, 54-57), and in differences at the level of brain physiology and in the prevalence of neurological and psychiatric disorders (57-59). In the current review we focus on the sex differences in the human hypothalamus and adjacent areas.

When observed by our group, the structural difference in the intermediate nucleus of the human hypothalamus (InM) (60-62) was at first termed "the sexually dimorphic nucleus of the preoptic area (SDN-POA)" (63). We found this nucleus to be 2.5 times larger in men than in women and to contain 2.2 times as many cells (63). Allen et al., (64) described four interstitial nuclei of the anterior hypothalamus (INAH1-4) and found, in men compared to women, a larger volume of the INAH3 and INAH2 subdivisions (respectively 2.8 and 2 times greater). The fact that they could not find a sex difference in INAH1 (= SDN-POA), as found by us (63), could be fully explained by the strong age effect on the sex dif- ferences of this nucleus $(58,65)$. In fact, the sex difference develops only after the age of 5 years and disappears temporarily after the age of 50 years $(63,66,67)$. Moreover, it is now clear that what we called the SDNPOA (63) is actually a horseshoe-shaped structure that can show up in sections as two separate nuclei $(58,62)$, which Allen et al., (64) called INAH1 and 2, or as just one nucleus, called the intermediate nucleus (62) or SDN-POA (63). Further analysis of INAH1 and 2 in the transsexual population is ongoing, and confirms the presence of a clear sex difference in adult controls up to 50 years of age.

We recently localized and delineated the uncinate nucleus (Un) using three different stainings, i.e. thionin, neuropeptide-Y and synaptophysin. We found sex differences in volume and neuron number in the INAH3 subdivision while no differences were found for INAH4 (68, Fig. 1). The INAH3 volume size and the presence of a sex difference in INAH3 volume size fully agreed with previously reported data $(54,64,69,70)$, as did the sex difference for the number of neurons in INAH3. A number of different names have been used to refer to the two Un subnuclei (68): i) periventricular and uncinate nucleus (the former closer to the third ventricle than the latter) (61); ii) INAH4 (closer to the third ventricle than the INAH3) (64); and, most recently, iii) lateral and medial subdivisions of the Un (62). In view of the evidence provided by neurochemical markers such as neuropeptide- $Y$ and synaptophysin, and the fact that they appear as one structure in some subjects, there are indeed arguments in favor of considering these two subdivisions a single structure called the Un. Koutcherov et al. also suggested that the Un was the homolog of the rat central subdivision of the medial preoptic nucleus (MPOc) (62) that, in this animal, is clearly related to the brain network for input and output of male sexual behavior $(17,71)$. Moreover, INAH3 was found in male-to-female (MtF) transsexual people to be small (of female size and cell number), while the INAH4 subdivision did not show gender-related differences, morphological or otherwise, between men and women (68; Fig. 1). In addition, sex differences were found in the INAH3 volume as delineated by neuropeptide $\mathrm{Y}$, but not in INAH4.

Other sex differences have been found in the human anterior commissure, the interthalamic adhesion and in the corpora mamillaria $(58,72)$.

\section{Sex hormone receptors and neurosteroids}

Sex hormone receptors, too, are expressed in a sexually dimorphic way in the human hypothalamus and adjacent areas.

In most hypothalamic areas that show androgen receptor (AR) staining, nuclear staining, in particular, is less intense in women than in men. The strongest sex difference was found in the lateral and the medial mamillary nucleus (MMN; 73). The mamillary body complex is known to be involved in several aspects of sexual behavior, such as arousal of sexual interest and penile erection $(58,73,74)$. In addition, a sex difference in AR staining was present in the horizontal diagonal band of Broca, SDN-POA, medial preoptic area (MPO), dorsal and ventral zone of the periventricular nucleus (PVN), supraoptic nucleus (SON), ventromedial hypothalamic 
nucleus, and infundibular nucleus (INF). However, no sex differences were observed in AR staining in the adult bed nucleus of the stria terminalis (BST), the nucleus basalis of Meynert, and the islands of Calleja (73). No differences related to male sexual orientation were found in nuclear AR activity in the mamillary complex, this activity not being found to differ in heterosexual men compared with homosexual men, but it was significantly stronger than in women. A female-like pattern was found in 26- and 53-year-old castrated men and in intact old men. These data indicate that the amount of nuclear receptor staining in the adult mamillary complex is dependent on the circulating levels of androgens rather than on gender identity or sexual orientation. This idea is supported by the fact that a male-like pattern of AR staining was found in a 36-year-old bisexual non-castrated MtF transsexual (T6) and a heterosexual virilized woman aged 46 (5), while a female-like pattern for INAH3 volume and number of cells was found in the former patient (T6) (68).

Various sex differences have been observed for estrogen receptor $\alpha(E R \alpha)$ staining in the hypothalamus and adjacent areas of young adult human subjects. More intense nuclear $E R \alpha$ immunoreactivity was found in young men compared with young women, for example, in the SDN-POA, the SON, and the PVN. Women showed a stronger nuclear $\mathrm{ER} \alpha$ immunoreactivity in the suprachiasmatic nucleus (SCN) and MMN. No sex differences in nuclear $E R \alpha$ staining were found in, for example, the central subdivision of the bed nucleus of the stria terminalis (BSTc), the islands of Calleja, or in the INF. More intense nuclear ER $\beta$ staining was found in men, for example, in neurons of the BSTc, the islands of Calleja, and the SDN-POA. Women showed more nuclear ERB staining in the SCN, the SON, the PVN, the INF and the MMN (75). Observations in subjects with abnormal hormone levels showed, in most areas, ER $\beta$ immunoreactivity distribution patterns that were consistent with the level of circulating estrogens, suggesting that the majority of the reported sex differences in ER $\beta$ immunoreactivity are "activational" rather than "organizational" in nature $(76,77)$.

In the BSTc, differences in sex hormone receptors such as $E R \alpha, E R \beta$, the $A R$ and progesterone receptor (PR), are present from fetal age onward. More nuclear ER $\beta$ was observed in females than in males during the fetal/neonatal ages, whereas there were no overt sex differences in the other three sex hormone receptors detected. In adult men ER $\alpha$ and PR immunoreactivity was more pronounced in the BSTc of men than in women (9). Hence, the sensitivity of the BSTc for the different sex hormones depends strongly on sex and age.

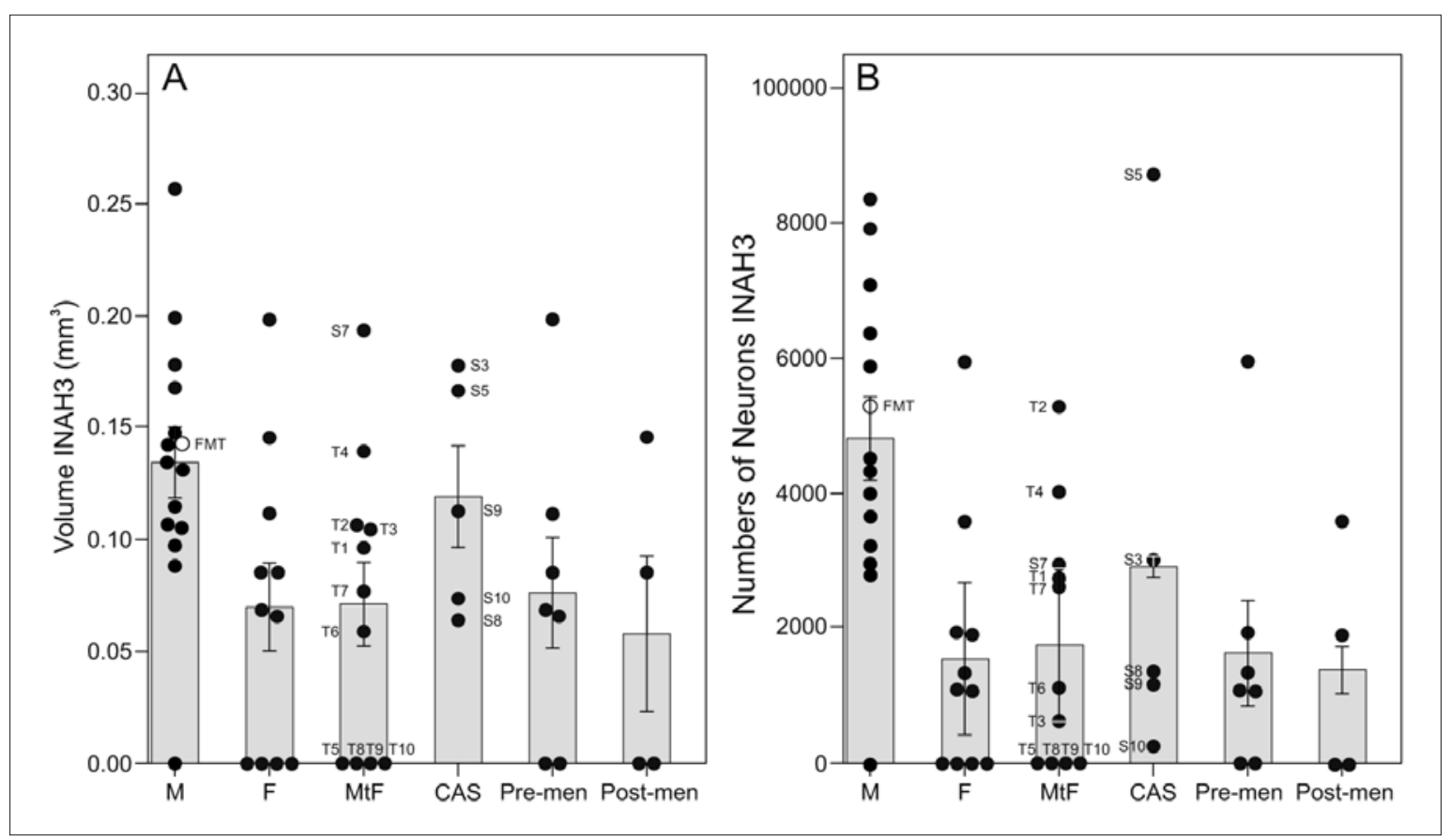

Figure 1 - A) INAH3 volume in thionin staining in different groups, according to their gender identity and hormonal changes in adulthood. (M) control male group, (F) control female group, (MtF) male-to-female transsexual group, (CAS) castrated male group, (Pre-men) premenopausal women, (Post-men) postmenopausal women. Bars represent means and standard errors of the mean (SEM). MtF and F groups were statistically different compared to the $M$ group $(p<0.018$ and $p<0.013$, respectively). Hormonal changes in adulthood (CAS versus $\mathrm{M}$ and Pre-men versus Post-men groups) showed no difference in INAH3 volume. Note that the volume of the female transsexual subject (FMT, in the male group, 51 years old) is in the male range, while the gender dysphoric MtF subject, who was not treated in any way (S7, in the MtF group, 84 years old), showed a male value for INAH3 volume. B) Distribution of the INAH3 number of neurons between different groups. Bars represent means and standard errors of the mean (SEM). Statistically significant differences were found between men $(M)$ and women $(F)(p<0.029)$ and between men $(M)$ and MtF transsexual groups $(p<0.002)$. FMT, in the male group, had a masculine INAH3 number of neurons and S7, in the MtF group, had a similar number of neurons to the other transsexuals examined. From Garcia-Falgueras and Swaab, 2008; Fig.s 5 and 6, with permission (ref. 68). 


\section{Transsexuality}

There is a vast array of factors that may lead to gender problems (Table I). Twin and family research has shown that genetic factors play a part $(78,79)$. Rare chromosomal abnormalities may lead to transsexuality (80), and it was recently found that polymorphisms of the genes for $E R \alpha$ and $E R \beta, A R$ repeat length polymorphism, and polymorphisms in the aromatase or CYP17 gene also produced an increased risk $(79,81,82)$.

Abnormal hormone levels during early development may play a role, as suggested by the high frequency of polycystic ovaries, oligomenorrhea and amenorrhea in female-to-male (FtM) transsexuals. This observation suggests early intrauterine exposure of the female fetus to abnormally high levels of testosterone (83). A recent study did not confirm a significantly increased prevalence of polycystic ovary syndrome. However, there was a significantly higher prevalence of hyperandrogynism in FtM transsexuals, also indicating the possible involvement of high testosterone levels in transsexuality (84). A girl with congenital adrenal hyperplasia $(\mathrm{CAH})$, who has been exposed to extreme levels of testosterone in utero, will also have an increased chance becoming transsexual. Although the likelihood of transsexuality developing in such cases is $300-1000$ greater than normal, the risk for transsexuality in $\mathrm{CAH}$ is still only $1-3 \%(85)$, whereas the probability of serious gender problems is $5.2 \%$ (86). The consensus is, therefore, that girls with $\mathrm{CAH}$ should be raised as girls, even when they are masculinized (24).

Epileptic women who were given phenobarbital or diphantoin during pregnancy also have an increased risk of giving birth to a transsexual child. Both these substances change the metabolism of the sex hormones and can act on the sexual differentiation of the child's brain. In a group of 243 women who had been exposed to such substances during pregnancy, Dessens et al. (87) found three transsexual children and a few others with less radical gender problems; these are relatively high rates for such a rare condition. On the "DES sons" (diethylstilbestrol, an estrogen-like substance - see later) website they claim that transsexuality occurs in $35.5 \%$ and a gender problem in $14 \%$ of the DES cases $(88,89)$. This is alarming, but needs, of course, to be confirmed in a formal study. There are no indications that postnatal social factors could be responsible for the occurrence of transsexuality (90).

Only in $23 \%$ of cases does a childhood gender problem lead to transsexuality in adulthood. With regard to sexual orientation, the most likely outcome of childhood gender identity disorder is homosexuality or bisexuality $(78$, 91-93).

\section{Transsexuality and the brain}

The theory on the origins of transsexuality is based on the fact that the differentiation of sexual organs takes place during the first couple of months of pregnancy, before the sexual differentiation of the brain. As these two processes have different timetables, it is possible, in principle, that they take different routes under the influence of different factors. If this is the case, one might expect to find, in transsexuals, female structures in a male brain and vice versa, and indeed, we did find such reversals in the central nucleus of the BSTc and in the INAH3, two brain structures that, in rats, are involved in many aspects of sexual behavior $(17,58)$. However, a gender identity test for rats does not exist, and this hypothesis can therefore be studied only in humans.

We found a clear sex difference in the human BSTc and INAH3. In men the BSTc area was twice that found in women and contained twice as many somatostatin neurons $(94,95)$. The same was true of the INAH3, which was found to be 1.9 times larger in men than in women and to contain 2.3 times as many neurons (68; Fig. 1). In relation to sexual orientation, no difference was found in the size or number of neurons in the BSTC area, while for the INAH3 the volume has previously been found to be related to sexual orientation, being larger in heterosexual than in homosexual men $(54,70)$. In MtF transsexuals we found a completely female BSTc and INAH3. Until now we have only been able to obtain material from one FtM transsexual, and his BSTc and INAH3 indeed turned out to have all the male characteristics. We were able to exclude the possibility that the reversal of sex differences in the BSTC and INAH3 were caused by changing hormone levels

Table I - Prenatal factors that influence gender identity (the feeling of being a man or a woman) and that may result in transsexuality.

\begin{tabular}{ll}
\hline Genetic factors & - Rare chromosomal disorders $(80)$. \\
& - Twin studies $(78,79)$. \\
& - Polymorphisms in ER $\beta$, androgen receptor and aromatase genes $(81,82)$. \\
& \\
& - Phenobarbital/diphantoin taken by pregnant mother $(88)$. \\
& - Hormones, cloacal exstrophy $(44,45)$. \\
& $-5 \alpha$-reductase-2 or $17 \beta$-hydroxy-steroid-dehydrogenase-3 deficiency $(34,42,43)$. \\
& - Girls with CAH $(85,86,112)$. \\
& - Complete androgen insensitivity syndrome results in XY heterosexual females with \\
& female identity $(41)$. \\
& - DES sons: $25 \%$ gender problems $(88,89)$.
\end{tabular}

Social factors? $\quad$ - Postnatally no evidence $(29,31,58,90)$.

Abbreviations: $\mathrm{CAH}=$ congenital adrenal hyperplasia; $\mathrm{DES}=$ diethylstilbestrol. 
in adulthood $(68,94,95)$, and it therefore seems that we are dealing with a developmental effect. Our observations thus support the above-mentioned neurobiological theory about the origin of transsexuality. The size of the BSTC and the INAH3 and their number of neurons match the gender that transsexuals feel they belong to, and not the sex of their sexual organs, birth certificate or passport. Unfortunately, the sex difference in the BSTc volume does not become apparent until early adulthood (96), meaning that this nucleus cannot be used for early diagnosis of transsexualism.

One person we studied had untreated male gender dysphoria (S7), took no hormones and kept his transsexual feelings under wraps. He appeared to have a large INAH3 volume - in the male range - but a female INAH3 number of neurons (68) and a female BSTc somatostatin neuron number (95). Hence, this individual's hypothalamic characteristics were mid-way between male and female values.

In transsexual MtF patients who receive hormonal treatment, some intermediate values, between those typical for men and women, have been found for lateralization and cognitive performance (90). Recently, functional reversals have been reported in the brains of transsexual people. A functional magnetic resonance imaging (fMRI) study in non-homosexual MtF transsexual people (i.e. erotically attracted to women), who were not treated hormonally, showed that a number of brain areas in the transsexual hypothalamus were activated by pheromones in a sex-atypical way. Although the functional reactions in the hypothalamus to an estrogen-derived pheromone were predominantly female, MtF transsexual people also showed some characteristics of a male activation pattern (97). When viewing erotic stimuli, MtF transsexual people before treatment tended to display female-like cerebral processing on fMRI (98).

\section{Sexual orientation: heterosexuality, homosexuality and bisexuality}

Sexual orientation in humans is also determined during early development, under the influence of our genetic background and factors that influence the interactions between the sex hormones and the developing brain (Table II).
The apparent impossibility of getting someone to change their sexual orientation is a major argument against the importance of the social environment in the emergence of homosexuality, as well as against the idea that homosexuality is a lifestyle choice. The mind boggles at the methods used in the attempt to bring about changes in sexual orientation: hormonal treatments such as castration, administration of testosterone or estrogens (treatments that appeared to affect libido but not sexual orientation); psychoanalysis; apomorphine administered as an emetic in combination with homo-erotic pictures; psychosurgery (lesions in the hypothalamus); electroshock treatment; chemical induction of epileptic insults; and imprisonment. As none of these interventions has led to a well-documented change in sexual orientation (99), there can be little doubt that our sexual orientation is fixed by the time we reach adulthood and is beyond further influence. Changes in sexual orientation in adulthood have been described - e.g. from heterosexual to pedophile - but only in cases of brain tumors in the hypothalamus and prefrontal cortex $(100,101)$. However, even these devastating changes in the hypothalamus cannot be interpreted in terms of functional changes in particular neuronal circuits. There are also claims that pedophiles and homosexual men have switched to heterosexual behavior as a result of stereotactical psychosurgery (lesions in the nucleus ventromedialis) (102), but these interventions are not only ethically questionable, they also do not meet any scientific standards. There are also some recent reports postulating that the sexual orientation of homosexual women, more than that of homosexual men, may sometimes change, either spontaneously or under the influence of psychotherapy (103). The effectiveness of therapy and the absence of bisexuality has, however, never been convincingly demonstrated in these cases.

The presence of a substantial genetic component in the development of sexual orientation is apparent from family and twin studies $(14,104)$. However, exactly which genes play a role is not yet clear. According to LeVay and Hamer (105), the size of the genetic component in homosexuality for both sexes is over $50 \%$. A number of genetic studies have suggested maternal transmission, indicating X-linked inheritance. The X-chromosome has accumulated genes involved in sex, reproduction and cognition. A meta-analysis of four linkage studies sug-

Table II - Prenatal factors that may influence sexual orientation (homosexuality, heterosexuality, bisexuality)

\begin{tabular}{ll}
\hline Genetic factors & - Twin studies $(14,104,105)$. \\
& - Molecular genetics $(58)$. \\
Hormones & - Girls with CAH $(58,85,112)$. \\
& - DES $(58,113)$. \\
Chemical factors & - Prenatal exposure to nicotine, amphetamines or thyroid medication $(117,118)$. \\
Immune response & - Homosexual orientation in men is most likely to occur in men with a large number of older \\
& brothers $(115,116)$. \\
Social factors? & - Stress in the mother during pregnancy $(117,119,120)$. \\
& - Being raised by transsexual or homosexual parents does not affect sexual orientation (121).
\end{tabular}

Abbreviations: $\mathrm{CAH}=$ congenital adrenal hyperplasia; $\mathrm{DES}=$ diethylstilbestrol. 
gested that Xq28 plays an important role in male homosexuality (106). However, 16 years after the initial findings the exact genes involved have not yet been identified (14). A different technique also indicated a role for the X-chromosome in male sexual orientation. Women with gay sons appeared to have an extreme skewing of $\mathrm{X}$-inactivation as compared to mothers without gay sons (107). Although this unusual methylation pattern supports a possible role of the X-chromosome in male homosexuality, its mechanism of action is far from clear. Given the complexity of the development of sexual orientation, it is likely to involve many genes. A genomewide linkage screening indeed identified several chromosomal regions and candidate genes for further exploration (108).

Whatever the exact nature of the genetic factor, it is interesting that such a factor has stayed present in the population throughout human history, given that homosexuals do not tend to procreate as much as the rest of the population. A good explanation could be that the genetic factors that are responsible for homosexuality also have a beneficial effect on the procreation of the population. Indeed, Camperio Ciani et al. (109) have found that the women on a homosexual male's mother's side tend to be more fertile. This antagonistic inheritance that promotes fecundity in females and a homosexual orientation in males is partly linked to the $\mathrm{X}$ chromosome (110).

Abnormal hormone levels originating from the child itself during intrauterine development may influence sexual orientation, as is apparent from the large percentage of bisexual and homosexual girls with $\mathrm{CAH}$ $(85,111,112)$. Between 1939 and 1960 some two million pregnant women in the US and Europe were prescribed diethylstilbestrol (DES) in order to prevent miscarriage. DES is an estrogen-like substance that actually turned out not to prevent miscarriage; furthermore, it was also found, in small dosages, not only to give a slightly elevated risk of cervical cancer but also to increase the chance of bisexuality or homosexuality in girls $(111,113)$ (but see 114).

The chance that a boy will be homosexual increases with the number of older brothers he has. This phenomenon is known as the fraternal birth order effect and is putatively explained by an immunological response by the mother to a product of the $Y$ chromosome of her sons. The chance of such an immune response to male factors would increase with every pregnancy resulting in the birth of a son $(115,116)$.

Prenatal exposure to nicotine, amphetamines, or thyroid-gland hormones increases the chances of giving birth to lesbian daughters $(117,118)$.

A stressed pregnant woman has a greater chance of giving birth to a homosexual son $(117,119)$ or a lesbian daughter (120) (Table II).

Although it has often been postulated that postnatal development is also important for the direction of sexual orientation, there is no solid proof for this. On the contrary, children who were born after artificial insemination with donor sperm and who were raised by a lesbian couple are heterosexually oriented (121). There is also no proof for the idea that homosexuality is the result of a deficient upbringing, or that it is a "lifestyle choice" or an effect of social learning (99). It is curious therefore, that some children are still forbidden to play with homosexu- al friends, an unthinkable attitude left over from the idea that homosexuality is "contagious" or can be learned.

\section{Sexual orientation and the brain}

Clinical observations have shown the involvement of a number of brain structures in sexual orientation. It has been reported that in some patients with Klüver-Bucy syndrome, which involves lesions of the temporal lobe, orientation changed from heterosexual to homosexual. Shifts in sexual orientation (to homosexual and pedophile) have also been reported in connection with tumors in the temporal lobe and hypothalamus. Lesions in the preoptic area of the hypothalamus in experimental animals, such as ferrets and rats, produce shifts in sexual orientation (58). The exact function of the preoptic area is not well known, but it seems to be crucial for the approach to a sexual partner, since it is implicated in the recognition and integration of sensory stimuli such as sexual clues, in arousal mechanisms, and in copulatory behaviour and its motor expression $(58,71)$.

Several structural and functional differences in the brain have been described in relation to sexual orientation (for a review see 23). We found the first difference in the $\mathrm{SCN}$, or brain clock, which turned out to be twice as large in homosexual compared with heterosexual men (122). In an experiment with rats a similar difference could be induced by pharmacologically disturbing the interaction between testosterone and the developing brain around the time of birth, using the aromatase inhibitor ATD in the neonatal period. This experiment yielded bisexual adult rats which had larger numbers of cells in their SCN (123). The difference in the SCN was therefore not caused by a change in sexual behavior, as was suggested at the time, but by a disturbed interaction between sex hormones and the developing brain.

In 1991, LeVay (54) reported that homosexual men, just like heterosexual women, have a smaller volume of the frontal part of the hypothalamus (INAH3). In 1992, Allen and Gorski (55) reported that the anterior commissure of homosexual men is larger than that of heterosexual men. This structure, which is larger in women than in men, takes care of left-right connections within the temporal cortex, and is thus involved in sex differences in cognitive abilities and language. As shown by Savic and Lindström (53), this difference in size may possibly be related to the sex-atypical hemispheric asymmetries observed in homosexual men and homosexual women (23). No differences were found in the BSTc volume or number of somatostatin-expressing neurons in homosexual men compared to heterosexual men $(94,95)$.

Functional scanning has recently also shown differences in the hypothalamus in relation to sexual orientation. The first functional scanning paper to point out differences in the hypothalamus in relation to sexual orientation, by Kinnunen et al. (124), did not receive much scientific or public attention, although it may have clinical consequences. The hypothalamus of homosexual men turned out not to be as responsive to a classic antidepressant (fluoxetine) as that of heterosexual men, which suggests a different kind of activity of the serotonergic system. Savic et al. (52) used scent, a pheromone derived from progesterone and excreted in perspiration in concentrations that are 10 times higher in men than in 
women. Pheromones influence sexual behavior and stimulate activation in the hypothalamus of heterosexual women and homosexual men in the same way, but the one used in this study not elicit a PET response in the hypothalamus of heterosexual men. Apparently heterosexual men are not stimulated by a male scent, which suggests that pheromones contribute to determining our behavior in relation to our sexual orientation (125). In a follow-up study (126), lesbian women, as compared to heterosexual women, reacted in a sexatypical, almost reciprocal way to pheromones. These observations, too, show that there are hypothalamic circuits that function in a way that depends on our sexual orientation. Indeed, viewing erotic videos of heterosexual or homosexual content produced activation in the hypothalamus, detectable by fMRI, but only when subjects were viewing videos of their respective sexual orientation (127). Another fMRI study using such an approach showed activation of different neural structures outside the hypothalamus. In homosexual men, the left angular gyrus, left caudate nucleus and right pallidum were activated. In contrast, heterosexual men showed activation of the bilateral lingual gyrus, right hippocampus and right parahippocampal gyrus (128). A further study extends these findings to cortical areas. Using fMRI, activity changes in the brain were measured while pictures of men and women were shown. Looking at a female face made the thalamus and medial prefrontal cortex of heterosexual men and homosexual women react more strongly, whereas in homosexual men and heterosexual women these structures reacted more strongly to the face of a man (129).

Savic's previous studies raised the question of whether certain sexually dimorphic features in the brain, which are unlikely to be directly involved in reproduction, may differ between homosexual and heterosexual individuals. This issue was explored by studying hemispheric asymmetry, using volumetric MRI, and functional connectivity of the amygdala, using PET measurements of cerebral blood flow (53). Volumetric measurements in heterosexual men and homosexual women showed a rightward cerebral asymmetry, whereas the volumes of the cerebral hemispheres were symmetrical in homosexual men and heterosexual women (53). Moreover, homosexual subjects also showed sex-atypical amygdala connections. In homosexual men, as in heterosexual women, the connections were more widespread from the left amygdala. In homosexual women and heterosexual men, on the other hand, they were more widespread from the right amygdala. Furthermore, in homosexual men and heterosexual women the connections displayed were primarily with the contralateral amygdala and the anterior cingulate, while in heterosexual men and homosexual women the connections displayed were primarily displayed with the caudate, putamen, and the prefrontal cortex (53). Dichotic listening performance has also been found to show a greater right ear advantage in heterosexual men as compared to heterosexual women, while lesbian women were somewhat masculinized in their functional cerebral asymmetry (130).

These studies show sex-atypical cerebral asymmetry and functional connections in homosexual subjects that cannot be primarily linked to reproduction, and suggest a linkage between sexual orientation and neurobiological entities.

\section{Concluding remarks}

The human fetal brain develops in the male direction through a direct action of testosterone and in the female direction through the absence of this hormone. During the intrauterine period, gender identity (the conviction of belonging to the male or female gender), sexual orientation, cognition, aggression and other behaviors are programmed in the brain in a sexually differentiated way. Sexual differentiation of the genitals takes place in the first two months of pregnancy, whereas sexual differentiation of the brain starts in the second half of pregnancy. This means that in the event of an ambiguous sex at birth, the degree of masculinization of the genitals may not reflect the degree of masculinization of the brain. Our observations on reversed sex differences in the brains of transsexual people support the idea that transsexuality is based on an opposite sexual differentiation of i) sexual organs during the first couple of months of pregnancy and ii) the brain in the second half of pregnancy. There is no proof that the social environment after birth has an effect on the development of gender or sexual orientation, while the possible effects on sexual differentiation of the brain by endocrine disrupters in the environment and in medicines given to the pregnant mother should be investigated.

The differences observed in the INAH3 in relation to sexual orientation and gender identity and this structure's possible connection with the BSTc suggest that these two nuclei and the two earlier described nuclei that were found to be related to gender and sexual orientation, i.e. the SDN-POA (= intermediate nucleus = INAH1 and 2) and SCN, are all part of a complex network involved in various aspects of sexual behavior. Neurobiological research on sexual orientation and gender identity in humans is only just gathering momentum, but the evidence shows that humans have a vast array of brain differences, related not only to gender, but also to sexual orientation. There is a need for further multidisciplinary research on the putative influence of testosterone in development, e.g. in individuals with complete androgen-insensitivity syndrome.

\section{Acknowledgements}

We thank Bart Fisser, Unga Unmehopa, Rawien Balesar, Arja A. Sluiter, Joop Van Heerikhuize and Ton Puts for their technical help, Wilma Verweij for her secretarial help, Jenneke Kruisbrink for her literature resource help and Mrs Terry Reed, Dr Michel Hofman and Dr Ronald W.H. Verwer for their critical comments. Brain material was provided by the Netherlands Brain Bank (coordinator Dr Inge Huitinga). Financial support was obtained from CajaMadrid Bank, from GIRES and Mermaids and from the Netherlands Institute for Neuroscience.

\section{References}

1. Swaab DF, Chung WC, Kruijver FP, Hofman MA, Hestiantoro A. Sex differences in the hypothalamus in the different stages of human life. Neurobiol Aging 2003;1:S1-S19

2. Phoenix $\mathrm{CH}$, Goy RW, Gerall AA, Young WC. Organizing action of prenatally administered testosterone propionate on 
the tissues mediating mating behaviour in the female guinea pig. Endocrinology 1959;65:369-382

3. Bakker J, De Mees C, Douhard Q et al. Alpha-fetoprotein protects the developing female mouse brain from masculinization and defeminization by estrogens. Nat Neurosci 2006;9:220-226

4. Bakker J, Baum MJ. Role for estradiol in female-typical brain and behavioral sexual differentiation. Front Neuroendocrinol 2008;29:1-16

5. Kruijver FP, Fernández-Guasti A, Fodor M, Kraan EM, Swaab DF. Sex differences in androgen receptors of the human mamillary bodies are related to endocrine status rather than to sexual orientation or transsexuality. J Clin Endocrinol Metab 2001;86:818-827

6. Swaab DF, Chung WC, Kruijver FP, Hofman MA, Ishunina TA. Structural and functional sex differences in the human hypothalamus. Horm Behav 2001;40:93-98

7. Kruijver FP, Swaab DF. Sex hormone receptors are present in the human suprachiasmatic nucleus. Neuroendocrinology 2002;75:296-305

8. Ishunina TA, Swaab DF. Estrogen receptor-alpha splice variants in the human brain. Gynecol Endocrinol 2008;24: 93-98

9. Chung WCJ. Doctoral Thesis: Sexual differentiation of the human and rodent forebrain: gonadal steroid receptors and apoptosis in the bed nucleus of the stria terminalis and medial preoptic nucleus. The Netherlands Institute for Neuroscience, University of Amsterdam, January 15th 2003

10. Gorski RA. Critical role for the medial preoptic area in the sexual differentiation of the brain. Prog Brain Res 1984; 61:129-146

11. Reisert I, Pilgrim C. Sexual differentiation of monoaminergic neurons-genetic or epigenetic? Trends Neurosci 1991;14: 468-473

12. Davies W, Wilkinson LS. It is not all hormones: alternative explanations for sexual differentiation of the brain. Brain Res 2006; 1126: 36-45

13. Mayer A, Lahr G, Swaab DF, Pilgrim C, Reisert I. The Ychromosomal genes SRY and ZFY are transcribed in adult human brain. Neurogenetics 1998;1:281-288

14. Bocklandt S, Vilain E. Sex differences in brain and behavior: hormones versus genes. Adv Genet 2007;59:245-266

15. Dewing $P$, Shi $T$, Horvath S, Vilain E. Sexually dimorphic gene expression in mouse brain precedes gonadal differentiation. Brain Res Mol Brain Res 2003;118:82-90

16. Lopes AM, Ross N, Close J, Dagnall A, Amorim A, Crow TJ. Inactivation status of PCDH11X: sexual dimorphisms in gene expression levels in brain. Hum Genet 2006;119:267275

17. Swaab DF. The human hypothalamus. Basic and clinical as pects. Part II: Neuropathology of the hypothalamus and adjacent brain structures. In: Aminoff MJ, Boller F, Swaab DF eds Handbook of Clinical Neurology. Amsterdam; Elsevier 2004:193-231

18. Finegan JA, Bartleman B, Wong PY. A window for the study of prenatal sex hormone influences on postnatal development. J Genet Psychol 1989;150:101-112

19. De Zegher F, Devlieger H, Veldhuis JD. Pulsatile and sexually dimorphic secretion of luteinizing hormone in the human infant on the day of birth. Pediatric Res 1992;32:605607

20. Quigley CA. Editorial: The postnatal gonadotropin and sex steroid surge-insights from the androgen insensitivity syndrome. J Clin Endocrinol Metab 2002;87:24-28

21. Swaab DF. Sexual differentiation of the human brain: relevance for gender identity, transsexualism and sexual orientation. Gynecol Endocrinol 2004;19:301-312
22. Swaab DF. Sexual diffentiation of the brain and behavior. Best Pract Res Clin Endocrinol Metab 2007;21:431-444

23. Swaab DF. Sexual orientation and its basis in brain structure and function. Proc Natl Acad Sci U S A 2008;105: 1027310274

24. Hughes IA, Houk C, Ahmed SF et al. Consensus statement on management of intersex disorders. Arch Dis Child 2006;91:554-563

25. Reiner WG. Assignment of sex in neonates with ambiguous genitalia. Curr Opin Pediatr 1999;11:363-365

26. Keenan JP, Wheeler MA, Gallup GG Jr, Pascual-Leone A. Self-recognition and the right prefrontal cortex. Trends Cogn Sci 2000;4:338-344

27. Ahmed SF, Morrison S, Hughes IA. Intersex and gender assignment; the third way? Arch Dis Child 2004;89:847-850

28. Money J. Ablatio penis: normal male infant sex-reassigned as a girl. Arch Sex Behav 1975;4:65-71

29. Colapinto J. As Nature Made Him. The Boy Who was Raised as a Girl. New York; Harper Collins Publishers Inc 2001

30. Money J, Erhardt AA. Man and Woman, Boy and Girl: The Differentiation and Dimorphism of Gender Identity from Conception to Maturity. Baltimore; Johns Hopkins University Press 1972

31. Diamond M, Sigmundson K. Sex reassignment at birth. Long-term review and clinical implications. Arch Pediatr Adolesc Med 1997;151:298-304

32. Bradley SJ, Oliver GD, Chernick AB, Zucker KJ. Experiment of nurture: ablatio penis at 2 months, sex reassignment at 7 months, and a psychosexual follow-up in young adulthood. Pediatrics 1998;102:e9

33. al-Attia HM. Gender identity and role in a pedigree of Arabs with intersex due to 5alpha reductase-2 deficiency. Psychoneuroendocrinology1996;21:651-657

34. Cohen-Kettenis PT. Gender change in 46,XY persons with 5alpha-reductase-2 deficiency and 17beta-hydroxysteroid dehydrogenase-3 deficiency. Arch Sex Behav 2005;34: 399410

35. Praveen EP, Desai AK, Khurana ML et al. Gender identity of children and young adults with 5alpha-reductase deficiency. J Pediatr Endocrinol Metab 2008;21:173-179

36. Reiner WG. Gender identity and sex-of-rearing in children with disorders of sexual differentiation. J Pediatr Endocrinol Metab 2005;18:549-553

37. Jürgensen M, Hiort O, Holterhus PM, Thyen U. Gender role behavior in children with XY karyotype and disorders of sex development. Horm Behav 2007;51:443-453

38. Garcia-Falgueras A, Pinos $\mathrm{H}$, Collado $\mathrm{P}$ et al. The role of the androgen receptor in CNS masculinization. Brain Res 2005; 1035:13-23

39. Morris JA, Jordan CL, Dugger BN, Breedlove SM. Partial demasculinization of several brain regions in adult male (XY) rats with a dysfunctional androgen receptor gene. J Comp Neurol 2005;487:217-226

40. Zuloaga DG, Puts DA, Jordan CL, Breedlove SM. The role of androgen receptors in the masculinization of brain and behavior: what we've learned from the testicular feminization mutation. Horm Behav 2008;53:613-626

41. Wisniewski AB, Migeon CJ, Meyer-Bahlburg HF et al. Complete androgen insensitivity syndrome: long term medical, surgical, and psychosexual outcome. J Clin Endocrinol Metab 2000; 85: 2664-2669

42. Imperato-McGinley J, Peterson RE, Gautier T, Sturla E. Male pseudohermaphroditism secondary to 5 alpha-reductase deficiency - a model for the role of androgens in both the development of the male phenotype and the evolution of a male gender identity. J Steroid Biochem 1979;11:637-645 
43. Wilson JD, Griffin JE, Russell DW. Steroid 5 alpha-reductase 2 deficiency. Endocr Rev 1993;14:577-593

44. Reiner WG, Gearhart JP. Discordant sexual identity in some genetic males with cloacal exstrophy assigned to female sex at birth. N Engl J Med 2004;350:333-341

45. Meyer-Bahlburg HF. Gender identity outcome in femaleraised $46, \mathrm{XY}$ persons with penile agenesis, cloacal exstrophy of the bladder, or penile ablation. Arch Sex Behav 2005; 34:423-438

46. Swaab DF, Hofman MA. Sexual differentiation of the human brain. A historical perspective. Prog Brain Res 1984;61: 361-374

47. Goldstein JM, Seidman LJ, Horton NJ et al. Normal sexual dimorphism of the adult human brain assessed by in vivo magnetic resonance imaging. Cereb Cortex 2001;11:490 497

48. Alonso-Nanclares L, Gonzalez-Soriano J, Rodriguez JR, DeFelipe J. Gender differences in human cortical synaptic density. Proc Natl Acad Sci U S A 2008;105:14615-4619

49. Amunts $K$, Schleicher A, Bürgel U, Mohlberg H, Uylings HB, Zilles K. Broca's region revisited: cytoarchitecture and intersubject variability. J Comp Neurol 1999;412:319-41

50. Amunts K, Schleicher A, Zilles K. Cytoarchitecture of the cerebral cortex-more than localization. Neuroimage 2007;37:1061-1065

51. Allen JS, Damasio H, Grabowski TJ, Bruss J, Zhang W. Sexual dimorphism and asymmetries in the gray-white composition of the human cerebrum. Neuroimage 2003; 18:880-894

52. Savic I. Brain imaging studies of the functional organization of human olfaction. Chem Senses 2005;30:222-223

53. Savic I, Lindström P. PET and MRI show differences in cerebral asymmetry and functional connectivity between homoand heterosexual subjects. Proc Natl Acad Sci U S A 2008;105:9403-9408

54. LeVay S. A difference in hypothalamic structure between heterosexual and homosexual men. Science 1991;253: 1034-1037

55. Allen LS, Gorski RA. Sexual orientation and the size of the anterior commissure in the human brain. Proc Natl Acad Sci U S A 1992;89:7199-7202

56. Hines M. Sex steroids and human behavior: prenatal androgen exposure and sex-typical play behavior in children. Ann N Y Acad Sci 2003;1007:272-282

57. Savic I, Engel J Jr. Sex differences in patients with mesial temporal lobe epilepsy. J Neurol Neurosurg Psychiatry 1998;65:910-912

58. Swaab DF. The human hypothalamus. Basic and clinical aspects. Part I: Nuclei of the hypothalamus. In: Aminoff MJ, Boller F, Swaab DF eds Handbook of Clinical Neurology. Amsterdam; Elsevier 2003:127-140

59. Bao AM, Swaab DF. Gender difference in age-related number of corticotropin-releasing hormone-expressing neurons in the human hypothalamic paraventricular nucleus and the role of sex hormones. Neuroendocrinology 2007;85:27-36

60. Brockhaus H. Beitrag zur normalen Anatomie des Hypothalamus und der Zona incerta beim Menschen. J Psychol Neurol 1942;51:96-196

61. Braak $\mathrm{H}$, Braak $\mathrm{E}$. The hypothalamus of the human adult: chiasmatic region. Anat Embryol (Berl) 1987;175:315-330

62. Koutcherov Y, Paxinos G, Mai JK. Organization of the human medial preoptic nucleus. J Comp Neurol 2007;503: $392-406$

63. Swaab DF, Fliers E. A sexually dimorphic nucleus in the human brain. Science 1985;228:1112-1115

64. Allen LS, Hines M, Shryne JE, Gorski RA. Two sexually di- morphic cell groups in the human brain. J Neurosci 1989; 9:497-506

65. Swaab DF, Hofman MA. Sexual differentiation of the human hypothalamus: ontogeny of the sexually dimorphic nucleus of the preoptic area. Brain Res Dev Brain Res 1988;44:314318

66. Hofman MA, Swaab DF. The sexually dimorphic nucleus of the preoptic area in the human brain: a comparative morphometric study. J Anat 1989;164:55-72

67. Swaab DF, Gooren LJ, Hofman MA. The human hypothalamus in relation to gender and sexual orientation. Prog Brain Res 1992;93:205-219

68. Garcia-Falgueras A, Swaab DF. A sex difference in the hypothamaic uncinate nucleus: relationship to gender identity. Brain 2008;131:3132-3146

69. Byne W, Lasco MS, Kemether E et al. The interstitial nucle of the human anterior hypothalamus: an investigation of sexual variation in volume and cell size, number and density. Brain Res 2000;856:254-258

70. Byne W, Tobet S, Mattiace LA et al. The interstitial nuclei of the human anterior hypothalamus: an investigation of variation with sex, sexual orientation, and HIV status. Horm Behav 2001;40:86-92

71. Schober JM, Pfaff D. The neurophysiology of sexual arousal. Best Pract Res Clin Endocrinol Metab 2007;21: 445-461

72. Allen LS, Gorski RA. Sexual dimorphism of the anterior commissure and massa intermedia of the human brain. J Comp Neurol 1991;312:97-104

73. Fernández-Guasti A, Kruijver FP, Fodor M, Swaab DF. Sex differences in the distribution of androgen receptors in the human hypothalamus. J Comp Neurol 2000;425:422-435

74. MacLean PD, Ploog DW. Cerebral representation of penile erection. J Neurophysiol 1962;25:29-55

75. Ishunina TA, Fischer DF, Swaab DF. Estrogen receptor alpha and its splice variants in the hippocampus in aging and Alzheimer's disease. Neurobiol Aging 2007;28:16701681

76. Kruijver FP, Balesar R, Espila AM, Unmehopa UA, Swaab DF. Estrogen receptor-alpha distribution in the human hypothalamus in relation to sex and endocrine status. J Comp Neurol 2002;454:115-139

77. Kruijver FP, Balesar R, Espila AM, Unmehopa UA, Swaab DF. Estrogen-receptor-beta distribution in the human hypothalamus: similarities and differences with ER alpha distribution. J Comp Neurol 2003;466:251-277

78. Coolidge FL, Thede LL, Young SE. The heritability of gender identity disorder in a child and adolescent twin sample. Behav Genet 2002;32:251-257

79. Hare L, Bernard P, Sánchez FJ et al. Androgen receptor repeat length polymorphism associated with male-to-female transsexualism. Biol Psychiatry 2009;65:93-96

80. Hengstschläger $M$, van Trotsenburg $M$, Repa $C$, Marton $E$, Huber JC, Bernaschek G. Sex chromosome aberrations and transsexualism. Fertil Steril 2003 Mar;79(3):639-40

81. Henningsson S, Westberg L, Nilsson S et al. Sex steroid-related genes and male-to-female transsexualism. Psychoneuroendocrinology 2005;30:657-664

82. Bentz EK, Hefler LA, Kaufmann U, Huber JC, Kolbus A, Tempfer CB. A polymorphism of the CYP17 gene related to sex steroid metabolism is associated with female-to-male but not male-to-female transsexualism. Fertil Steril 2008; 90:56-59

83. Padmanabhan V, Manikkam M, Recabarren S, Foster D. Prenatal testosterone excess programs reproductive and metabolic dysfunction in the female. Mol Cell Endocrinol 2005;246:165-174 
84. Mueller A, Gooren LJ, Naton-Schötz S, Cupisti S, Beckmann MW, Dittrich R. Prevalence of polycystic ovary syndrome and hyperandrogenemia in female-to-male transsexuals. J Clin Endocrinol Metab 2008;93:1408-1411

85. Zucker KJ, Bradley SJ, Oliver G, Blake J, Fleming S, Hood J. Psychosexual development of women with congenital adrenal hyperplasia. Horm Behav 1996;30:300-318

86. Dessens AB, Slijper FM, Drop SL. Gender dysphoria and gender change in chromosomal females with congenital adrenal hyperplasia. Arch Sex Behav 2005;34:389-397

87. Dessens AB, Cohen-Kettenis PT, Mellenbergh GJ, vd Poll N, Koppe JG, Boer K. Prenatal exposure to anticonvulsants and psychosexual development. Arch Sex Behav 1999;28: 31-44

88. Gender Identity Research and Education Society, information page: http://www.gires.org.uk/genderdev.php

89. DES sons' International Research Network: http://www.antijen.org/transadvocate/id33.html

90. Cohen-Kettenis PT, van Goozen SH, Doorn CD, Gooren LJ. Cognitive ability and cerebral lateralisation in transsexuals. Psychoneuroendocrinology 1998;23:631-641

91. Cohen-Kettenis PT, Gooren LJ. Transsexualism: a review of etiology, diagnosis and treatment. J Psychosom Res 1999; 46:315-333.

92. Cohen-Kettenis PT, Delemarre-van de Waal HA, Gooren LJ. The treatment of adolescent transsexuals: changing insights. J Sex Med 2008;5:1892-1897

93. Wallien MS, Cohen-Kettenis PT. Psychosexual outcome of gender-dysphoric children. J Am Acad Child Adolesc Psychiatry 2008;47:1413-1423

94. Zhou JN, Hofman MA, Gooren LJ, Swaab DF. A sex difference in the human brain and its relation to transsexuality. Nature 1995;378:68-70

95. Kruijver FP, Zhou JN, Pool CW, Hofman MA, Gooren LJ, Swaab DF. Male-to-female transsexuals have female neuron numbers in a limbic nucleus. $\mathrm{J}$ Clin Endocrinol Metab 2000;85:2034-2041

96. Chung WC, De Vries GJ, Swaab DF. Sexual differentiation of the bed nucleus of the stria terminalis in humans may extend into adulthood. J Neurosci 2002;22:1027-1033

97. Berglund H, Lindström P, Dhejne-Helmy C, Savic I. Male-tofemale transsexuals show sex-atypical hypothalamus activation when smelling odorous steroids. Cereb Cortex 2008;18:1900-1908

98. Gizewski ER, Krause E, Schlamann M et al. Specific cerebral activation due to visual erotic stimuli in male-to female transsexuals compared with male and female controls: an fMRI study. J Sex Med 2009;6:440-448

99. LeVay S. Queer Science. The Use and Abuse of Research into Homosexuality. Cambridge, MA; MIT Press 1996

100. Miller BL, Cummings JL, Mclntyre H, Ebers G, Grode M. Hypersexuality or altered sexual preference following brain injury. J Neurol Neurosurg Psychiatry 1986;49:867-873

101. Burns JM, Swerdlow RH. Right orbitofrontal tumor with pedophilia symptom and constructional apraxia sign. Arch Neurol 2003;60:437-440

102. Dieckmann G, Hassler R. Treatment of sexual violence by stereotactic hypothalamotomy. In: Sweet WH, Obrador S, Martin-Rodriguez JG eds Neurosurgical Treatment in Psychiatry, Pain, and Epilepsy. Baltimore; University Park Press 1977:451-462

103. Spitzer RL. Can some gay men and lesbians change their sexual orientation? 200 Participants reporting a change from homosexual to heterosexual orientation. Arch Sex Behav 2003;32:403-492

104. Bailey JM, Bell AP. Familiality of female and male homosexuality. Behav Genet 1993;23:313-22
105. LeVay S, Hamer DH. Evidence for a biological influence in male homosexuality. Sci Am 1994;270:44-49

106. Hamer DH, Hu S, Magnuson VL, Hu N, Pattatucci AM. A linkage between DNA markers on the $X$ chromosome and male sexual orientation. Science 1993;261:321-327

107. Bocklandt S, Horvath S, Vilain E, Hamer DH. Extreme skewing of $\mathrm{X}$ chromosome inactivation in mothers of homosexual men. Hum Genet 2006;118:691-694

108. Mustanski BS, Dupree MG, Nievergelt CM, Bocklandt S, Schork NJ, Hamer DH. A genomewide scan of male sexual orientation. Hum Genet 2005;116:272-278

109. Camperio Ciani A, Corna F, Capiluppi C. Evidence for maternally inherited factors favouring male homosexuality and promoting female fecundity. Proc Biol Sci 2004;271: 22172221

110. Iemmola F, Camperio Ciani A. New evidence of genetic factors influencing sexual orientation in men: female fecundity increase in the maternal line. Arch Sex Behav 2009;38:393399

111. Meyer-Bahlburg HF, Ehrhardt AA, Rosen LR. Prenatal estrogens and the development of homosexual orientation. Developmental Psychology 1995;31:12-21

112. Meyer-Bahlburg HF, Gruen RS, New Ml et al. Gender change from female to male in classical congenital adrenal hyperplasia. Horm Behav 1996;30:319-332

113. Ehrhardt AA, Meyer-Bahlburg HF, Rosen LR et al. Sexual orientation after prenatal exposure to exogenous estrogen. Arch Sex Behav 1985;14:57-77

114. Titus-Ernstoff L, Perez K, Hatch EE et al. Psychosexual characteristics of men and women exposed prenatally to diethylstilbestrol. Epidemiology 2003;14:155-160

115. Blanchard R. Fraternal birth order and the maternal immune hypothesis of male homosexuality. Horm Behav 2001; 40:105-114

116. Bogaert AF. The interaction of fraternal birth order and body size in male sexual orientation. Behav Neurosci 2003; 117:381-384

117. Ellis L, Cole-Harding S. The effects of prenatal stress, and of prenatal alcohol and nicotine exposure, on human sexual orientation. Physiol Behav 2001;74:213-226

118. Ellis L, Hellberg J. Fetal exposure to prescription drugs and adult sexual orientation. Personality and Individual Differences 2005;38:225-236

119. Ellis L, Ames MA, Peckham W et al. Sexual orientation of human offspring may be altered by severe maternal stress during pregnancy. Journal of Sex Research 1988;25:152157

120. Bailey JM, Willerman L, Parks C. A test of the maternal stress theory of human male homosexuality. Arch Sex Behav 1991;20:277-293

121. Green R. Sexual identity of 37 children raised by homosexual or transsexual parents. Am J Psychiatry 1978;135: 692697

122. Swaab DF, Hofman MA. An enlarged suprachiasmatic nucleus in homosexual men. Brain Res 1990;537:141-148

123. Swaab DF, Slob AK, Houtsmuller EJ, Brand T, Zhou JN. Increased number of vasopressin neurons in the suprachiasmatic nucleus (SCN) of 'bisexual' adult male rats following perinatal treatment with the aromatase blocker ATD. Brain Res Dev Brain Res 1995;85:273-279

124. Kinnunen LH, Moltz H, Metz J, Cooper M. Differential brain activation in exclusively homosexual and heterosexual men produced by the selective serotonin reuptake inhibitor, fluoxetine. Brain Res 2004;1024:251-254

125. Savic I, Berglund H, Lindström P. Brain response to putative pheromones in homosexual men. Proc Natl Acad Sci U S A 2005;102:7356-7361 
126. Berglund $\mathrm{H}$, Lindström $\mathrm{P}$, Savic I. Brain response to putative pheromones in lesbian women. Proc Natl Acad Sci U S A 2006;103:8269-8274

127. Paul T, Schiffer B, Zwarg T et al. Brain response to visual sexual stimuli in heterosexual and homosexual males. Hum Brain Mapp 2008;29:726-735

128. Hu SH, Wei N, Wang QD et al. Patterns of brain activation during visually evoked sexual arousal differ between homo- sexual and heterosexual men. AJNR Am J Neuroradio 2008;29:1890-1896

129. Kranz F, Ishai A. Face perception is modulated by sexual preference. Curr Biol 2006;16:63-68

130. Rahman Q, Cockburn A, Govier E. A comparative analysis of functional cerebral asymmetry in lesbian women, heterosexual women, and heterosexual men. Arch Sex Behav 2008;37:566-571 